\title{
Erratum to: Reassessing the risk of natalizumab-associated PML
}

\author{
Joseph R. Berger ${ }^{1,2} \cdot$ Robert J. Fox ${ }^{1,2}$
}

Published online: 29 March 2016

(C) Journal of NeuroVirology, Inc. 2016

Eratum to: J. Neurovirol.

DOI 10.1007/s13365-016-0427-6

There are some errors in the first column of Table 1. The corrected Table 1 follows.

The online version of the original article can be found at http://dx.doi.org/ 10.1007/s13365-016-0427-6.

Joseph R. Berger

joseph.berger@uphs.upenn.edu

1 Multiple Sclerosis Division of the Department of Neurology, University of Pennsylvania, 3400 Spruce St., 3 W Gates,

Philadelphia, PA 19104, USA

2 Mellen Center for Multiple Sclerosis Treatment and Research, Neurological Institute, Cleveland Clinic, Cleveland, OH, USA 
Table 1 Contemporary estimates of risks of natalizumab-associated PML

\begin{tabular}{|c|c|c|c|c|}
\hline JCV serology & Previous immunosuppressant therapy & Overall risk & Risk up to 24 months of therapy & Risk after 24 months of therapy \\
\hline \multirow[t]{2}{*}{ Negative } & No & $\sim 1: 7749$ & $\sim 1: 45,798$ & $\sim 1: 5022$ \\
\hline & Yes & $\sim 1: 2733$ & $\sim 1: 16,151$ & $\sim 1: 1171$ \\
\hline \multirow[t]{2}{*}{ Positive } & No & $\sim 1: 194$ & $\sim 1: 1145$ & $\sim 1: 126$ \\
\hline & Yes & $\sim 1: 68$ & $\sim 1: 404$ & $\sim 1: 44$ \\
\hline \multicolumn{5}{|l|}{ Anti-JCV antibody positive } \\
\hline Natalizumab exposure & No prior immunosuppressant use & & Prior immunosuppressant use & \\
\hline $1-<24$ months & $<1: 1000$ & & $2.5 / 1000$ & \\
\hline$\geq 24$ months* & $8 / 1000$ & & $23 / 1000$ & \\
\hline JCV serology & Previous immunosuppressant therapy & Overall risk & Risk up to 24 months of therapy & Risk after 24 months of therapy \\
\hline \multirow[t]{2}{*}{ Negative } & No & $\sim 1: 7749$ & $\sim 1: 45,798$ & $\sim 1: 5022$ \\
\hline & Yes & $\sim 1: 2733$ & $\sim 1: 16,151$ & $\sim 1: 1171$ \\
\hline \multirow[t]{2}{*}{ Positive } & No & $\sim 1: 194$ & $\sim 1: 1145$ & $\sim 1: 126$ \\
\hline & Yes & $\sim 1: 68$ & $\sim 1: 404$ & $\sim 1: 44$ \\
\hline \multicolumn{5}{|l|}{ Anti-JCV antibody positive } \\
\hline Natalizumab exposure & No prior immunosuppressant use & & Prior immunosuppressant use & \\
\hline $1-<24$ months & $<1: 1000$ & & $2.5 / 1000$ & \\
\hline$\geq 24$ months* & $8 / 1000$ & & $23 / 1000$ & \\
\hline
\end{tabular}

* including cases of PML diagnosed up to 114 infusions

Biogen Data on File 